\title{
A trabalhadora rural e a exposição ocupacional no cultivo do tomate
}

\author{
The rural worker and the occupational exposure in growing
} tomatoes

\author{
Marilei de Melo Tavares e Souza ${ }^{1}$ - Fabiana Ramos Vargas ${ }^{2} \bullet$ Pamela dos Santos Costa $^{3}$ • Antônio Marcos Gomes Tosoli ${ }^{4}$ \\ - Carlos Marcelo Balbino ${ }^{5}$ Joanir Pereira Passos ${ }^{6}$
}

\begin{abstract}
RESUMO
O estudo teve por objetivo identificar a percepção da mulher rural sobre sua exposição ocupacional no cultivo do tomate. Pesquisa descritivo-exploratória, realizada em localidades rurais que cultivam agricultura tomateira, na cidade de Vassouras, Rio de Janeiro/RJ. A escolha do cenário deve-se ao fato de grande número de mulheres trabalharem nestes espaços agrícolas. Além disto, o desenvolvimento da atividade de Agente Comunitária de Saúde promoveu familiaridade com o campo de estudo e viabilidade através da unidade de Estratégia Saúde da Família (ESF) correspondente. Participaram do estudo 20 mulheres adultas que trabalham no cultivo do tomate. $\mathrm{O}$ instrumento utilizado para coleta de dados foi um questionário com 10 perguntas, levando em consideração aspectos referentes à saúde, exposição ocupacional e percepção frente a sua prática diária no manejo da agricultura em questão. Observou-se que, $25 \%$ dessas mulheres trabalham mais de 10 horas por dia, somente $35 \%$ delas usam Equipamento de Proteção Individual (EPI) e 65\% das agricultoras não relacionam seu problema de saúde com seu ambiente de trabalho. Em síntese, o estudo traz contribuições para novas pesquisas no contexto da saúde da mulher rural como fator determinante para prevenção e promoção da saúde.
\end{abstract}

Palavras-chave: Enfermagem; Saúde da Mulher Rural; Exposição Ocupacional.

\begin{abstract}
The aim of this study was to identify the perception of rural women about their occupational exposure to tomato growing. Descriptive-exploratory research, carried out in rural localities that cultivate tomato agriculture, in the city of Vassouras, Rio de Janeiro / RJ. The choice of scenario is due to the large number of women working in these agricultural spaces. In addition, the development of the Community Health Agent activity promoted familiarity with the field of study and viability through the corresponding Family Health Strategy unit. 20 adult women working in tomato cultivation participated in the study. The instrument used for data collection was a questionnaire with 10 questions, taking into account aspects related to health, occupational exposure and perception regarding their daily practice in the management of the agriculture in question. It was observed that $25 \%$ of these women works more than 10 hours a day, only $35 \%$ of them use Personal Protective Equipment (PPE) and $65 \%$ of the women farmers does not relate their health problem to their work environment. In summary, the study brings contributions to new research in the context of rural women's health as a determinant factor for prevention and health promotion.
\end{abstract}

Keywords: Nursing; Health Rural Women; Occupational exposure.

${ }^{1}$ Psicóloga, Pós-Doutorado em andamento - UERJ. Doutora em Ciências pelo Programa de Pós-graduação em Enfermagem e Biociências - UNIRIO. Professora do Curso de Especialização em Enfermagem do Trabalho, da Escola de Enfermagem Aurora de Afonso Costa, da Universidade Federal Fluminense - EEAAC/UFF, RJ. Professora do Curso de Graduação em Enfermagem -USS. Supervisora Pedagógica do Curso de Especialização em Enfermagem em UTI - USS e Editora Executiva da Revista Pró-UniverSUS. Brasil. Email: marileimts@hotmail.com

${ }^{2}$ Enfermeira. Servidora-Enfermeira na Secretaria Municipal de Vassouras, RJ.Graduada pela Universidade Severino Sombra/USS. Brasil. Email: fabyrv.ana@hotmail.com

${ }^{3}$ Enfermeira. Pós-Graduanda no Curso de Enfermagem em UTI da Universidade Severino Sombra/USS. Servidora-Enfermeira da Secretaria Municipal de Miguel Pereira, RJ. Brasil. Email: pamela_91scosta@yahoo.com

${ }^{4}$ Doutor em Enfermagem. Professor Titular da Escola de Enfermagem da Universidade do Estado do Rio de Janeiro - UERJ, Rio de Janeiro, Brasil. E-mail: mtosoli@gmail.com ${ }^{5}$ Enfermeiro. Mestre em Enfermagem pela Universidade Federal Fluminense/MPEA/UFF. Professor da Universidade Severino Sombra - USS e Centro de Ensino Superior de Valença CESVA/FAA - Faculdade de Enfermagem de Valença. Doutorando do Programa do Programa em Ciências do Cuidado em Saúde pela Universidade Federal Fluminense UFF. Brasil.Email: carlosmbalbino@hotmail.com. Autor correspondente.

${ }^{6}$ Enfermeira. Professora Titular da Escola de Enfermagem Alfredo Pinto da Universidade Federal do Estado do Rio de Janeiro/UNIRIO. Doutora em Enfermagem pela Universidade de São Paulo/USP. Mestrado em Enfermagem pela Universidade Federal do Estado do Rio de Janeiro/UNIRIO. Coordenadora do Doutorado em Enfermagem e Biociências PPGENFBIO/UNIRIO. Orientadora de Doutorado e Mestrado Acadêmico em Enfermagem - PPGENF/UNIRIO. Brasil. Email:joppassos@hotmail.com 


\section{INTRODUÇÃO}

As condições de trabalho no cultivo da monocultura do tomate, na zona rural são precárias, nem sempre saudáveis e muitas vezes prejudiciais à sua saúde. Além da exposição aos agrotóxicos, há o fato de que tratando-se de um ambiente externo, as mulheres rurais encontram-se expostas às mudanças climáticas que podem gerar riscos biológicos como os fatores de radiação ultravioleta (UV), radiação ultravioleta do tipo $\mathrm{A}$ (UVA) e radiação ultravioleta do tipo $B(U V B)$ emitidos pelos raios solares. Estes podem causar diversos problemas, desde uma desidratação acentuada ao câncer de pele. Seguindo neste raciocínio estão expostas à altas temperaturas podendo desenvolver possíveis problemas respiratórios e podem acarretar diversas complicações na saúde desta trabalhadora.

Durante o cultivo de tomate, estas mulheres passam longos períodos em pé e muitas vezes com uma postura inadequada, que potencializa a predisposição para os problemas ergonômicos e circulatórios, com o surgimento de varizes.

A desigualdade de gênero aparece claramente, pelo fato das mulheres rurais executarem as mesmas atividades e carga horária dos homens e receberem menos pela sua mão-de-obra, gerando a necessidade de trabalharem horas a mais para receberem a mesma quantia. Existe ainda a questão da escolaridade, pois, pesquisas sugerem que a maioria das pessoas que trabalha no campo possui pouca ou nenhuma escolaridade, o que dificulta a percepção dos riscos a que estão expostas, tornando este olhar mais restrito ${ }^{1}$.

Embora o setor agrícola venha passando por uma grande modernização, encontramos muitos trabalhadores que continuam expostos a vários riscos ocupacionais, seja pelo fato da sua atividade que por vezes exige uma postura incorreta, trabalharem ao ar livre e consequentemente ficarem expostos aos raios solares durante um longo período de trabalho².

Apesar do marcante aumento da participação das mulheres no mercado de trabalho, no Brasil, ainda persiste um desconhecimento generalizado sobre os efeitos na saúde do trabalhador. O papel do gênero feminino sempre esteve ligado às questões reprodutivas e, que resultam na necessidade de estratégias variadas de conciliação entre a tripla jornada que envolve as atividades profissionais, domésticas e mulher. A inserção social das mulheres no trabalho suscitou que as autoridades governamentais e a sociedade civil repensem nas teorias, conceitos, fontes de informação, para dar conta da complexidade e das especificidades das condições de trabalho e da inserção das mulheres que outrora pertenciam ao âmbito privado e agora estão no público ${ }^{3}$.

Deste modo, percebe-se que a participação da mulher em espaços produtivos, como a agricultura avança tanto quanto à percepção subjetiva de seu reconhecimento, principalmente por elas mesmas, que passam a se ver como conhecedoras e mediadoras do processo. Bem como de um aspecto não menos relevante, frente às desigualdades de gênero que são patentes no processo produtivo orientado pelas relações patriarcais, nas quais a mulher sempre é considerada em um papel secundário ${ }^{3}$.

$\mathrm{Na}$ agricultura familiar é comum à todos, inclusive a própria mulher, o papel de coadjuvante, a ajudante do marido, o que sustenta os estereótipos da divisão sexual do trabalho, no qual a mulher realiza o - trabalho leve o que é totalmente relativo, pois a mesma que julga-se inferior, por ocupar-se de tarefas mais leves, entretanto, realiza diversas atividades que dependem de vários graus de esforço físico.

No que diz respeito ao labor é factível e facilmente verificável sua excessiva jornada de trabalho, assim, a mulher dedica tempo à agricultura, ao doméstico e aos filhos e filhas, o que caracteriza uma tripla jornada. $\mathrm{Ou}$ seja, a mulher rural é ajudante de seu companheiro na agricultura, e muitas vezes não é nem considerada como uma profissional da agricultura, detentora dos direitos trabalhistas outorgados por lei. A mulher rural permanece inserida no âmbito privado, tendo como profissão: o lar, e no seu ambiente doméstico, na maioria das famílias, as tarefas domésticas permanecem sobre sua responsabilidade, para quando a mesma terminar sua jornada na roça. Acarretando uma carga horária estressante e de grande esforço para essas mulheres, que são mães, donas de casa e agricultoras. E todo esse estresse pode contribuir para distúrbios psicoemocionais e somáticos ${ }^{3}$.

A relevância desta temática dá-se pela escassez de produção científica à respeito da temática em questão. A Política Nacional de Atenção Integral à Saúde da Mulher (PNAISM), após um balanço técnico realizado pela Área Técnica da Saúde da Mulher, identifica ainda a necessidade de articulação com outras áreas técnicas e da proposição de novas ações, quais sejam: atenção às mulheres portadoras de necessidades especiais, negras, rurais, indígenas, presidiárias e lésbicas e a participação nas discussões e atividades sobre saúde da mulher e meio ambiente ${ }^{4}$.

0 estudo tem por objetivo identificar a percepção da mulher rural sobre sua exposição ocupacional no cultivo do tomate.

\section{MÉTODO}

Trata-se de uma pesquisa do tipo descritivo-exploratória com abordagem qualitativa, que trabalha com o universo de significados, motivos, aspirações, crenças, valores e atitudes, o que corresponde à um espaço mais profundo das relações, dos processos e dos fenômenos ${ }^{5}$.

Os cenários desta pesquisa foram diversas localidades rurais na cidade de Vassouras-RJ que cultivam a agricultura tomateira. Dentre elas podemos destacar: Capim Angola, Santa Rita e Pirauí, totalizando cerca de $50 \%$ de toda produção vassourense. A escolha destes cenários está pautada no grande número de mulheres que trabalha 
nestes espaços agrícolas. O contato com o cenário foi através da unidade de ESF correspondente. Com aprovação prévia da Secretaria Municipal de Saúde de Vassouras, RJ.

Foram participantes do estudo 20 mulheres adultas que trabalham no cultivo do tomate, independente de escolaridade, classe social, paridade e situação conjugal. As mulheres foram selecionadas de forma aleatória e localizadas a partir do seu cadastro na Estratégia Saúde da Família (ESF), cuja abrangência envolve sua moradia. Somase ainda que sua participação foi através da assinatura do Termo de Consentimento Livre e Esclarecido (TCLE), tendo como critérios para inclusão o grau de escolaridade e aceitação para participarem do estudo.

$\mathrm{O}$ instrumento utilizado para a coleta de dados foi a entrevista estruturada com 10 perguntas, que é aquela que pressupõe perguntas previamente formuladas com questões abertas, levando em consideração aspectos referentes à saúde, exposição ocupacional e sua percepção frente a prática diária no manejo da agricultura em questão ${ }^{5}$.

Foi garantido 0 anonimato das participantes atendendendo às exigências da Resolução 196/96 e Resolução 510/16 do Conselho Nacional de Saúde, que dispõem sobre as normas e diretrizes regulamentadoras de pesquisas envolvendo seres humanos. 0 projeto que originou o estudo, é um Trabalho de Conclusão de Curso, apresentado ao Curso de Enfermagem ${ }^{6}$ foi aprovado pelo Comitê de Ética em Pesquisa da Universidade Severino Sombra (CEP/USS). Obteve aprovação sob o n 046/2009-02.

A análise dos resultados deu-se a partir da modalidade temática da análise de conteúdo ${ }^{7}$. Na pré-análise selecionou-se o material, e, em seguida, realizou-se a leitura flutuante do mesmo, deixando-se impregnar pelo conteúdo, observou-se a dinâmica existente entre a questão norteadora inicial e as questões emergentes, complementando-as com a leitura de textos teóricos relacionados ao tema.

\section{RESULTADOS}

\section{Caracterização da Amostra}

Grande parte da amostra, cerca de $95 \%$ possui ensino fundamental incompleto, mais especificamente até a $4^{\circ}$ série primária, isso deve-se a falta de acesso a educação, já que as escolas que ofertam os demais níveis situavamse longe das comunidades rurais. Além da evasão escolar, devido à necessidade de se trabalhar na lavoura.

Quanto a situação conjugal das participantes, 75\% das mulheres são casadas. Logo, além do trabalho na agricultura, as mesmas ainda realizam o trabalho doméstico e o cuidado com os possíveis filhos, que é ainda tido como uma função exclusivamente feminina na maioria dos lares de nosso país.

A tabela 1 apresenta a faixa etária da população estudada, na qual podemos observar que a maioria, cerca de $70 \%$ das mulheres que trabalham, estão em idade fértil e toda esta exposição poderá acarretar em sérios problemas de saúde, posteriormente.

Tabela 1. Distribuição da idade das participantes por faixa etária. Vassouras, RJ, Brasil, 2017.

\begin{tabular}{c|c}
\hline Idade (em anos) & Percentual \\
\hline $26 \mid------35$ & $30 \%$ \\
\hline $36 \mid-----45$ & $40 \%$ \\
\hline $46 \mid-----60$ & $25 \%$ \\
\hline $61 \mid-----70$ & $05 \%$ \\
\hline Total & $100 \%$ \\
\hline
\end{tabular}

Fonte: dados da pesquisa.

\section{Trabalho da mulher na Agricultura}

Como podemos observar na tabela 2 abaixo, 70\% das participantes do estudo são multíparas, veem sua prole como força de trabalho, para auxiliar o casal na agricultura, daí a necessidade de se ter muitos filhos. Há mais preocupação com a quantidade, como força de trabalho do que com a qualidade, no que diz respeito a alimentação, educação e perspectiva de melhoria de vida para essas pessoas. Quanto a questão do aborto, 25\% entrevistadas tiveram essa experiência, segundo elas de forma espontânea e não souberam atribuir causas a esta intercorrência.

Tabela 2. Paridade das mulheres entrevistadas. Vassouras, RJ, Brasil, 2017.

\begin{tabular}{c|c}
\hline Frequência & Percentual \\
\hline Nenhum & $0 \%$ \\
\hline 01 filhos & $30 \%$ \\
\hline 02 filhos & $20 \%$ \\
\hline 03 filhos ou mais & $25 \%$ \\
\hline Abortos & $25 \%$ \\
\hline Total & $100 \%$ \\
\hline
\end{tabular}

Fonte: dados da pesquisa.

$\mathrm{Na}$ agricultura familiar é comum a todos, inclusive à própria mulher, o papel de coadjuvante, a ajudante do marido, o que sustenta os estereótipos da divisão sexual do trabalho, no qual a mulher realiza o - trabalho leve o que é totalmente relativo, pois a mesma que julga-se inferior, por ocupar-se de tarefas mais leves, entretanto, realiza diversas atividades que dependem de vários graus de esforço físico. A tabela 3 a seguir, relaciona-se à caracterização do trabalho, podemos observar que apenas uma pequena parte das mulheres entrevistadas, cerca de $30 \%$ trabalha para gerar sua própria renda, como diarista. A grande maioria, $70 \%$ da amostra, indica trabalhar para ajudar o marido. 
Tabela 3. Caracterização do trabalho das entrevistadas. Vassouras, RJ Brasil, 2017.

\begin{tabular}{c|c}
\hline Regime de trabalho & Percentual \\
\hline Diarista & $30 \%$ \\
\hline Ajuda o companheiro & $70 \%$ \\
\hline Total & $100 \%$ \\
\hline
\end{tabular}

Fonte: dados da pesquisa.

A tabela 4 refere o tempo de trabalho destinado ao cultivo do tomate, os dados mostram que as mulheres entrevistadas passam a maior parte de suas vidas na atividade agrícola, tendo assim uma visão de mundo limitada. Além de estarem grande parte de seu tempo, no manejo da plantação que exige delas grande esforço, o que pode levá-las ao envelhecimento precoce e queda na imunidade o que facilitará a manifestação de diversos problemas de saúde.

Tabela 4. Tempo de trabalho no cultivo de tomate. Vassouras, RJ, Brasil, 2017.

\begin{tabular}{c|c}
\hline Tempo de trabalho na lavoura & Percentual \\
\hline $05-10$ anos & $15 \%$ \\
\hline $11-15$ anos & $20 \%$ \\
\hline $16-25$ anos & $15 \%$ \\
\hline $26-35$ anos & $30 \%$ \\
\hline 36 anos ou mais & $20 \%$ \\
\hline Total & $100 \%$ \\
\hline
\end{tabular}

Fonte: dados da pesquisa.

Quanto à jornada de trabalho, na tabela 5, é claramente visível que a maioria dessas mulheres, 95\%, trabalha mais do que a jornada de trabalho considerada ideal, que é de 08 horas diárias. Porém esta situação agrava-se se considerarmos que, além da jornada na lavoura ainda há o tempo gasto nos afazeres domésticos.

Tabela 5. Jornada de trabalho das mulheres entrevistadas. Vassouras, RJ, Brasil, 2017.

\begin{tabular}{c|c}
\hline Jornada de trabalho & Percentual \\
\hline Menos de 5 horas & $0 \%$ \\
\hline 05 - 07horas & $05 \%$ \\
\hline 08 - 10horas & $70 \%$ \\
\hline 11 horas ou mais & $25 \%$ \\
\hline Total & $100 \%$ \\
\hline
\end{tabular}

Fonte: dados da pesquisa.

\section{Exposição ocupacional - um problema de saúde}

Dentre os fatores de deterioração da saúde, a exposição aos agrotóxicos, seja ambiental ou ocupacional, aguda ou crônica, constitui-se em uma das especificidades relacionadas aos agravos de saúde da população rural, podendo causar danos à saúde das mulheres trabalhadoras do campo.

$\mathrm{Na}$ tabela 6, observa-se que a maioria das mulheres não sabe o que é Equipamento de Proteção Individual (EPI), o que demostra falta de informação, de recursos e de conhecimento sobre os possíveis risco a que estão expostas no trabalho rural.

Tabela 6. Conhecimento do Equipamento de Proteção Individual (EPI). Vassouras, RJ, Brasil, 2017

\begin{tabular}{c|c}
\hline Sabe o que é EPI & Percentual \\
\hline SIM & $35 \%$ \\
\hline Não & $65 \%$ \\
\hline Total & $100 \%$ \\
\hline
\end{tabular}

Fonte: dados da pesquisa.

\section{Percepção das trabalhadoras após orientações sobre o que é EPI}

Foi feito um esclarecido para as entrevistadas sobre EPI de uma forma menos técnica e mais acessível, indagou-se sobre seu uso ou não. A seguir diante o exposto, foi indagado sobre o uso de EPI. Por que se deve fazer uso? E por que não uso? Diante disto foram gerados os seguintes resultados apresentados da tabela 7 abaixo,em que é possível perceber que após serem prestadas informações orientações sobre 0 uso do EPI no trabalho rural, cerda de $50 \%$ das participantes conseguiu fazer a correlação. 0 que demostra que 0 enfermeiro pode desempenhar um papel fundamental nesse cenário, com ações preventivas e educativas.

Tabela 7. Sobre o Uso do EPI. Vassouras, RJ, Brasil, 2017.

\begin{tabular}{c|c|cc}
\hline \multicolumn{4}{c}{ USO DO EPI } \\
\hline SIM & POR QUE & NÃO & POR QUE \\
\hline $50 \%$ & Protege do sol & $05 \%$ & $\begin{array}{c}\text { Prejudica o } \\
\text { trabalho }\end{array}$ \\
\hline $5 \%$ & $\begin{array}{c}\text { Evita } \\
\text { contaminação }\end{array}$ & $30 \%$ & Não pulveriza \\
\hline $15 \%$ & $\begin{array}{c}\text { Evita problemas } \\
\text { de saúde }\end{array}$ & $05 \%$ & Desconfortável \\
\hline 0 & Não respondeu & $05 \%$ & Não tem acesso \\
\hline Total $50,0 \%$ & & $05 \%$ & Não respondeu \\
\hline
\end{tabular}

Fonte: dados da pesquisa.

\section{Percepção das trabalhadoras sobre a importância do uso do EPI}

Ao serem perguntadas sobre a utilização do EPI, algumas falas das participantes do estudo se destacam 
por estarem relacionadas a proteção da saúde, como: evitar intoxicação e medo de doenças causadas pela exposição o câncer de pele e alergia. A percepção de problemas e doenças identificadas pelas trabalhadoras entrevistadas podem ser observadas nas transcrições a seguir:

"Uso por causa do sol uso Boné, calça comprida, blusa comprida". (P16)

“Uso chapéu e blusa para me proteger do sol ...". (P15)

“Uso para proteger minha saúde...". (P14); (P 08)

"Uso para proteger minha saúde, porque tenho medo de contrair alguma doença". (P13)

"Para evitar câncer de pele e para evitar intoxicação ...". (P 06)

"Uso por causa da pele. Para não dar câncer de pele...". (P 01)

“Para evitar contaminação da lavoura ...". (P 05)

"Para me proteger porque sou alergia... Proteger do sol e sobre a alergia até mesmo com o cheiro do agrotóxico e das folhas da plantação...". (P 02)

\section{Dificuldades e motivos para não utilização do EPI}

Algumas participantes apontaram diversos motivos insatisfatórios que justificam não usar o equipamento de proteção individual (EPI), destacando: maior facilidade para o trabalho, desconforto, não utiliza remédios, por não ter disponível. As dificuldades e motivos que levam ao não uso do EPI pelas trabalhadoras podem ser verificados nos depoimentos a seguir:

“Não uso porque eu não mexo com agrotóxico... Só calço luvas para colher...". (P03)

“Não uso porque é muito mais fácil trabalhar sem ... Porque incomoda, esquenta muito...". (P04)

“Porque eu não passo remédio...". (P07)

"Não uso porque eu nunca passei remédio na plantação...". (P09)

“Porque eu não gosto ...". (P11)

“Porque os donos da lavoura não dão...Tem só para ele...". (P12)

“Não passo veneno... Mas quando eu usava eu passava...". (P17)

\section{Uso dos agrotóxicos na agricultura e doenças percebidas pelas trabalhadoras - risco ocupacional}

A implantação dos agrotóxicos contribuiu para a alta na produtividade das plantações, pois estes controlavam as pragas em geral, que é o grande inimigo da agricultura, porém seu uso indiscriminado trouxe para a saúde humana, sérios danos.
As tabelas 8 e 9, relacionam-se à doenças percebidas ou não pelas participantes. Contudo podemos observar na tabela 8 que $35 \%$ das mulheres entrevistadas relatou não possuir doenças, seguida pela maioria cerca de $65 \%$ das participantes falou sobre suas patologias. Importante ressaltar que nesta tabela encontram-se todas as doenças relatadas, sendo que, algumas mulheres tinham mais de uma patologia. Devido ao grande número de manifestações patológicas, podemos constatar que o risco ocupacional que estas mulheres sofrem é no mínimo, ao que influencia em sua homeostasia.

Tabela 8. Patologias/doenças percebidas pelas participantes. Vassouras, RJ, Brasil, 2017.

\begin{tabular}{c|c|c}
\hline Categoria & Percentual & Doenças relatadas \\
\hline NÃO & $35 \%$ & Sem relato \\
\hline SIM & $65 \%$ & $\begin{array}{l}\text { "Hipertensão"; "Alergia"; "Asma”; } \\
\text { "Infecção Urinária"; "Epilepsia"; } \\
\text { "Sinusite"; "Refluxo gástrico"; } \\
\text { "Problema de Visão"; "Problema } \\
\text { de Coluna”; “Problema de rins"; } \\
\text { "Problema do sistema Nervoso" }\end{array}$ \\
\hline Total & $100,0 \%$ & \\
\hline
\end{tabular}

Fonte: dados da pesquisa.

Ainda atentando para as doenças relatadas pelas entrevistadas, ao serem indagadas se acreditavam que tais doenças tinham relação com seu trabalho na lavoura. Observa-se na tabela 9 que cerca de 20\% das mulheres mencionou haver relação entre as patologias relatadas com o seu trabalho.

Tabela 9. Relação das doenças relatadas com trabalho na lavoura. Vassouras, RJ, Brasil, 2017.

\begin{tabular}{c|c|c}
\hline Categoria & Frequência & Percentual \\
\hline Postura & 1 & \\
\hline Agravamento & 1 & \\
\hline $\begin{array}{c}\text { Incerteza da renda do } \\
\text { problema }\end{array}$ & 1 & $20 \%$ \\
\hline Tripla jornada & 1 & \\
\hline Idade & 7 & \\
\hline Hereditário & 1 & $85 \%$ \\
\hline Não atribuíram & 3 & \\
\hline Não respondeu & 2 & \\
\hline Ficaram em dúvida & 3 & \\
\hline Total & 20 & $100,0 \%$ \\
\hline
\end{tabular}

Fonte: dados da pesquisa.

\section{DISCUSSÃO}

Mulheres que trabalham no campo,geralmente possuem pouca ou nenhuma escolaridade. E isso faz com que a visão dessas mulheres torne-se mais restrita no que diz respeito 
as repercussões de sua exposição durante sua jornada de trabalho ${ }^{1}$. Vão de encontro com as mulheres participantes da pesquisa por apresentar baixa escolaridade devido as dificuldades de acesso à educação seguida pela evasão escolar por conta da necessidade de trabalhar.

A maioria das mulheres que participou do estudo são casadas, isso também interfere na jornada de trabalho, por ter que trabalhar, cuidar dos filhos e ainda, na maioria das vezes, realizar trabalho doméstico, ainda reconhecido como ocupação e/ou responsabilidade feminina.

Como uma das características idealizadas da agricultura familiar é a de que a família teria um comportamento unificado em torno de um mesmo objetivo, a manutenção da propriedade e do grupo familiar acima de tudo ${ }^{8}$.

Apesar do aumento da participação da mulher no trabalho, ainda persiste um desconhecimento sobre os efeitos do trabalho na sua saúde ${ }^{3}$.

Os efeitos nocivos de agrotóxicos para a saúde humana têm sido objeto de diversos estudos. A presença de substâncias em amostras de sangue humano, no leite materno e resíduos presentes em alimentos consumidos pela população em geral, aponta a possibilidade de ocorrência de anomalias congênitas, câncer, doenças mentais, disfunções na reprodução humana relacionadas ao uso de agrotóxicos em cultivos ${ }^{9}$.

0 adoecimento e efeitos sofridos por mulheres trabalhadoras têm sido um desafio para enfermagem, há necessidade do desenvolvimento de intervenções efetivas direcionadas para a assistência integral ${ }^{10}$.

Por terem uma rotina de exposição intensa ao sol e aos agrotóxicos ainda na juventude, trabalhadores rurais estão expostos a muitos fatores de risco, ocasionando o desenvolvimento do espessamento da pele, aumento do enrugamento e a maior incidência do câncer ${ }^{11}$. E são estes fatores de risco que levam os trabalhadores rurais à serem considerados um grupo de risco para o desenvolvimento do câncer de pele ${ }^{12}$.

A mulher agricultora ocupa uma posição subordinada e seu trabalho aparece geralmente como ajuda, quando esta trabalha tanto quanto os homens ou executam as mesmas atividades que eles ${ }^{13}$.

Como uma das características idealizadas da agricultura familiar é a de que a família teria um comportamento unificado em torno de um mesmo objetivo, a manutenção da propriedade e do grupo familiar acima de tudo, não se supõem que haja diferenças e tensões entre as gerações e entre os gêneros. Muitos projetos e programas têm refletido este equívoco, ao proporem alternativas sem levar em conta qual será o impacto das ações de cada membro da família, principalmente quando estas alternativas vêm alterar os espaços já conquistados pelas mulheres ${ }^{8}$.

A mulher encontra-se em uma situação desprivilegiada, pois não é considerada como agricultora, mas sim, somente a esposa do agricultor, ficando como adjuvante da obtenção da renda familiar, pois encarrega-se apenas do - trabalho leve -, segundo a concepção do homem, o que a leva a posição inferiorizada, caracterizando-se por salários mais baixos submetendo-a a maior carga horária para compensar essa questão de gênero.

É bastante contundente na sua análise de que, a agricultura familiar, mesmo nas suas formas mais democráticas não têm sido capaz de enfrentar as desigualdades de gênero, permanecendo um setor, no qual as mulheres têm a sua autonomia bastante restrita, e a sua cidadania negada, seja pelo Estado - através das políticas públicas - seja pela sociedade civil. Para esta autora $^{14}$, esta situação explica-se porque, tanto o Estado como os movimentos, trabalham com uma visão ideal de família, em que a pessoa mantém entre si fortes laços de complementariedade, mas permanecem articuladas por um poder central, exercido pelo - marido/pai.

Outros estudos ${ }^{13}$ demonstram que a maioria dessas mulheres labuta na agricultura da família durante todo o ano, de segunda a domingo, e participa de todas as atividades direta e indiretamente associadas à agricultura - trabalho agrícola, cuidado com os animais e comercialização da produção.

Apesar da mulher trabalhar toda uma carga horária sob intenso esforço físico nas plantações tomateiras, provavelmente está destinado a ela, os afazeres domésticos, visto que a mesma ocupa uma posição de auxiliadora e nada mais, na mão de obra rural.

Visto que, estudos mostram que a mulher rural permanece inserida no âmbito privado, tendo como profissão: o lar, e no seu ambiente doméstico, na maioria das famílias, as tarefas domésticas permanecem sobre sua responsabilidade, para quando a mesma terminar sua jornada na roça. Acarretando uma carga horária estressante e de grande esforço para essas mulheres, que são mães, donas de casa e agricultoras ${ }^{3}$.

O aumento da participação de mulheres em ocupações anteriormente restritas a trabalhadores do sexo masculino, exige uma atenção maior para a prevenção de ocorrências, que antes eram ignoradas. Percebemos a necessidade de estudos epidemiológicos que atualizem dados da exposição ocupacional dentro de uma perspectiva de gênero, para uma melhor elaboração do planejamento futuro da prevenção e dos cuidados que deverão ser tomados para evitar muitos problemas relacionados à saúde da mulher trabalhadora.

Todo esse excesso de jornada trabalhista faz com que essas mulheres vivam exclusivamente para suas atividades, pois o trabalho agrícola associado a seus afazeres domésticos ocupam todo o seu tempo, o que a impossibilita o aumento de seus níveis de escolaridade e/ ou capacitar-se afim de obter conhecimentos técnicos para o beneficiamento de seu plantio. Toda essa questão refletese nos baixos índices de escolaridade - ensino fundamental - apresentados pela população estudada.

Observa-se que a maioria das mulheres não sabe o que é Equipamento de Proteção Individual (EPI), essa 
realidade confirma estudos ${ }^{15}$, que geralmente a exposição ocupacional dos trabalhadores rurais ocorre por falta de informação ou por falta de recursos.

O esclarecimento populacional é considerado uma medida preventiva de baixo custo, estudos mostram que esta medida permite ainda a reavaliação ao longo dos anos expostos ${ }^{16}$.

Importância de políticas de saúde voltadas para promoção e prevenção do câncer de pele. A enfermagem deve agir neste cenário de prevenção para adoção de medidas de proteção de trabalhadoras que se expõem ao sol. Atuando na educação em saúde com visando a promoção da saúde e diagnóstico precoce do câncer de pele ${ }^{17}$.

A exposição ocupacional no meio rural é um sério desafio para os profissionais de saúde, principalmente na agricultura tomateira, que é um dos líderes em índices de agrotóxicos. Mas, além dos agrotóxicos, o problema devese também à indicadores sóciodemográficos anteriores, a inalação de poeira agrícola, exposição à fatores ambientais sem devida proteção, a resistência ao uso de EPIs, além do tempo de exposição a tudo isso ${ }^{18}$.

Geralmente a exposição ocupacional dos trabalhadores rurais ocorre por falta de informação ou por falta de recursos. Deste modo, os EPIs tendem a não ser utilizados no momento do preparo e utilização dos agroquímicos, até porque nem sempre estão adequados à realidade e ao clima que os trabalhadores brasileiros enfrentam. A atitude de desprezo ao risco não pode ser tomada ao pé da letra, como se o trabalhador desconhecesse por completo os riscos inerentes àquela atividade. Muito pelo contrário, tal estratégia suscita o pleno conhecimento do perigo, no qual o trabalhador acrescenta ao risco inerente ao processo de trabalho o seu próprio risco, como forma de minimizar ou simplesmente negar o outro, numa estratégia de ideologia defensiva. A principal função da ideologia defensiva seria propiciar ao trabalhador a sobrevivência em um ambiente/ processo de trabalho injurioso, por meio da constituição de um valor simbólico, no qual o trabalhador domina o perigo, e não vice-versa ${ }^{15}$.

A realização de educação em saúde feita por uma equipe multidisciplinar visando a assistência de qualidade e livre de riscos, levam à resultados positivos para os sujeitos e familiares ${ }^{19}$.

0 treinamento de enfermeiros para avaliação destas lesões pode iniciar-se ainda na graduação, preferencialmente com uso de fotografias. Ao programar uma ação de detecção precoce de câncer de pele,deve levarse em consideração estudos de evidência em pesquisa, associados ao nível de conhecimento que a equipe possui sobre o método e a avaliação. E a fim de conseguir avaliar um maior número de pessoas com fatores de risco, podem ser realizadas campanhas em eventos específicos para avaliar e orientar trabalhadores quanto à patologia, fatores de risco e sinais de alerta ${ }^{20}$.
Em um estudo sobre fatores de risco para o câncer de pele, dentre às ações preventivas realizadas pelos trabalhadores rurais, estão uso de boné ou chapéu diariamente e uso de calças compridas ${ }^{12}$.

Apesar de falta de informação, vemos que algumas entrevistadas possuem, percepção da exposição ocupacional que sofrem no decorrer de sua jornada de trabalho na agricultura tomateira. Falta de informação ou desconhecimento sobre os fatores nocivos do sol a pele, trazem prejuízos à saúde.

O equipamento mais utilizado para aplicação de agrotóxicos é o pulverizador manual costal, e os EPIs que devem ser utilizados durante a aplicação dos pesticidas, são basicamente máscaras, macacões próprios, botas e luvas.

A exposição à fatores de risco mecânicos e ambientais específicos é agravada pelos recursos materiais insuficientes e inadequados, que ocasionam condições inseguras no trabalho. Em algumas profissões podemos estimar uma gama de problemas relacionados ao trabalho, como: queixas de varizes, infecções urinárias, problemas de coluna e distúrbios psicoemocionais, alergias respiratórias e dermatológicas, calos nas cordas vocais e distúrbios da voz, entre outros problemas, sendo possível propor medidas de proteção à saúde dos trabalhadores 3 .

O quadro clínico das intoxicações agudas por agrotóxicos está relacionado à uma série de fatores, tais como: grupo químico do produto envolvido, intensidade e tempo de exposição, uso de medidas de proteção entre outros. De um modo geral, é seguido de manifestações alérgicas, fadiga, formigamentos, cefaleia, náusea, vômito, sudorese e salivação abundantes, tontura, lacrimejamento, dores e cólicas abdominais, convulsões, dificuldade respiratória, coma e até mesmo levar a óbito?.

\section{CONSIDERAÇÕES FINAIS}

O presente estudo buscou identificar a percepção da mulher rural sobre sua exposição ocupacional no cultivo do tomate.

Em relação a sua percepção quanto à exposição ocupacional, identificamos que é notória que a mesma ainda encontra-se muito limitada, visto que essas agricultoras preocupam-se mais com o trabalho em si do que com suas consequências, devido a sua necessidade de terminar o trabalho na plantação para posteriormente, realizar seus deveres de dona de casa, mãe e esposa.

Os resultados mostram que, grande parte destas mulheres preocupa-se demasiadamente com com a exposição ao sol, o que é certo. Mas não incomodam-se com a questão dos agrotóxicos, pois não atribui este problema à elas, segundo as mesmas, somente quem pulveriza a plantação que deve usar o EPI. Porém estudos analisados anteriormente mostram que o potencial de contaminação é o mesmo, tanto para o indivíduo que pulveriza quanto 
para o que realiza as demais atividades da monocultura estudada. A questão de gênero aparece claramente neste momento, pois somente o dono da lavoura, que é o marido/ chefe da família, que - passa - o agrotóxico na plantação e consequentemente, segundo depoimentos levantados, é quem possui algum material para proteção durante a realização deste manejo.

A questão da percepção do risco ocupacional torna-se mais preocupante quanto analisamos que, muitas mulheres apesar estarem cientes desta problemática, simplesmente não usam EPI porque não gostam ou incomoda. Vale apena ressaltar que 03 das 20 mulheres entrevistadas tiveram episódio de aborto espontâneo e não pode-se descartar a possibilidade de ser devido à sua atividade agrícola.

Fatores como o ambiente de trabalho insalubre, a tripla jornada além da inferiorização diante da figura masculina faz com que muitas dessas mulheres se sintam desestimuladas a procurarem melhorias para suas condições de trabalho e consecutivamente para sua vida, pois sabemos que estas passam mais de 08 horas diárias no cultivo do tomate e ainda realizam os afazeres domésticos que culturalmente, são destinados à elas.

A solução não é retirar essas mulheres da agricultura, mesmo porque, apesar das condições precárias, é partir destas atividades que elas geram sua renda de forma honesta. A solução é capacitá-las à cuidar de lavoura, a fim de tornar sua atividade menos dispendiosa, mas eficaz e produtiva, além de sensibiliza-las quanto ao risco da exposição ocupacional em suas vidas, de uma maneira mais individualizada, clara e objetiva. Porque saber que há riscos a saúde, todas sabem, porém há um descredito em relação à essas manifestações em seu organismo.

Em síntese, é necessário criar condições para que as trabalhadoras rurais continuem trabalhando na agricultura, contudo de maneira menos insalubre e mais reconhecida e protegida. Importante destacar que enfermeiros podem e devem desenvolver ações de promoção e prevenção aos riscos ocupacionais no meio rural, apontado em estudos como um dos desafios para o profissional de saúde, sobretudo na agricultura tomateira pelos altos índices de uso de agrotóxicos. Diante disto o enfermeiro pode atuar no cenário rural desenvolvendo ações preventivas e educativas tanto com os trabalhadores bem como as famílias, visando a promoção de saúde da trabalhadora rural para prevenção dos riscos ocupacionais presentes no cultivo do tomate.

\section{REFERÊNCIAS}

1. Guerra, MS, Sampaio DPA. Receituário agronômico. Rio de Janeiro: Globo, 1988.

2. Hayashide JM, Sgura RM, Camilo OA, Mayumi JS, Mie NS, Albuquerque $\mathrm{CZ}$, et al. Doenças de pele entre trabalhadores rurais expostos à radiação solar. Estudo integrado entre as áreas de Medicina do trabalho e Dermatologia. Rev Bras Med Trab. 2010;8(2):97-104.
3. Aquino EML, Menezes GMS, Marinho LFB. Mulher, Saúde e Trabalho no Brasil: Desafios para um Novo Agir. Cad. Saúde Públ., RJ. 1995 abr/jun.; 11(2): 281-290.

4. Brasil. Política nacional de atenção integral à saúde da mulher: princípios e diretrizes. Brasília: Ministério da Saúde, 2004.

5. Minayo MCS, Carlos EA, Coimbra JR. Antropologia, Saúde e envelhecimento. Rio de Janeiro. Ed: FIOCRUZ, 2002.

6. Vargas FR, Carinhanha JI, Souza MMT. Exposição ocupacional no cultivo do tomate: a percepção da mulher rural. [Monografia]. Vassouras (RJ): Universidade Severino Sombra; 2009.

7. Bardin L. Análise de conteúdo. Ed. revista e ampliada. Lisboa: Edições 70; 2011.

8. Teixeira ZA. Perspectiva de gênero na produção rural. Org. Teixeira,Z.; Carvalho, H.M.; Suárez, M. e Souza, J. Brasília: IPEA, 1994.

9. Parez F, Moreira JC. É veneno ou é remédio? Agrotóxicos, saúde e ambiente. Rio de Janeiro: FIOCRUZ, 2003.

10. Nunes NCF, Souza MMT. Reflexões sobre a repercussão do câncer de mama para o binômio cliente-família. Revista PróUniverSUS. 2015 jul./dez.; 06 (3): 23-25.

11. Gaetano DE, Hodge B, Clark A, Ackerman S, Burdick P, Cook MLW. Preventing skin cancer among a farming population. AAOHN Journal. 2009; 57(1).

12. Espíndola EA. Risk perception analysis of the use of pesticides in rural areas: a study together with farmers in the city of Bom Repouso (MG) [Tese]. São Carlos: Universidade de São Paulo Escola de Engenharia de São Carlos; 2011.

13. Melo LA. Injustiças de Gênero: o trabalho da mulher na agricultura familiar. XIII Encontro da Associação Brasileira de Estudos Populacionais.MG Fundação Joaquim Nabuco do Sistema Fabril. Rio de Janeiro: Paz Terra, 2002.

14. Gouveia T. Muito trabalho e nenhum poder marcam a vida das mulheres. Observatório da Cidadania, 2003:46-51.

15. Silva CC, Egry EY. Constituição de competências para a intervenção no processo saúde-doença da população: desafio ao educador de enfermagem. Rev Esc Enferm USP. 2003; 37(2):11-6.

16. Iranzo CC, Rubia-Ortí JEnrique DL, Castillo SS, Firmino-Canhoto J. Lesões cutâneas malignas e pré-malignas: conhecimentos, hábitos e campanhas de prevenção solar. Acta paul. enferm. 2015;28(1):2-6.

17. Bernardes AV. Prevenção do câncer de pele em trabalhadores do setor agrícola. Revista Pró-UniverSUS. 2016. jul./dez.; 07 (3): 03-07.

18. Fidelis Cl, Balbino CM, Souza MMT, Rodrigues LMS, Silvino ZR, Passos JP. Dificuldades enfrentadas pelo paciente renal para a realização do tratamento. Revista Enfermagem Atual/In Derme. [on-line] 2016; 77 abril /maio /junho:16-21.

19. Paula, LLRJ, AP Silva, And JC Brandao. Fatores de Risco e Ações Preventivas para o Câncer de pele em Trabalhadores Rurais. European Journal of Surgical Cancer 2015; 41, supl. 1.

20. Bauer A, Hault K, Püschel A, Rönsch H, Knuschke P, Beissert S. Acceptance and Usability of Different Sunscreen Formulations among Outdoor Workers: A Randomized, Single-blind, Crossover Study. Acta Derm Venereol. 2013; 94(2):152-6. 